\section{International Scientific Journal Theoretical \& Applied Science}

\author{
p-ISSN: 2308-4944 (print) e-ISSN: 2409-0085 (online) \\ Year: 2017 Issue: 12 Volume: 56
}

\section{Sergey Alexandrovich Mishchik}

Associate Professor,

Candidate of Pedagogical Science, Academician of International Academy TAS, Assistant professor Department of Physics, State Maritime University Admiral Ushakov, Russia, sergei_mishik@mail.ru

Published: $30.12 .2017 \quad$ http://T-Science.org

SECTION 21. Pedagogy. Psychology. Innovation in Education

\title{
SYSTEMIC PROBLEMS EARTH MAGNETISM OF APPLIED PHYSICS MARITIME FLOT OF PEDAGOGOMETRIC ANALYSIS
}

\begin{abstract}
The basic principles of the system of problems earth magnetism in applied physics Navy pedagogometric analysis of the formation of mathematical models of learning activities about the nature of achieving the criteria of life, cycling, systemsness and phasing, which form a basic cell of the educational space, as well as prima nenie twelve pointed star Ertsgammy relatively presentation ertsgamming principle which determines the foundations pedagogometric through forming substantive methods of hyper-space professional life, psychological and educational activity theory, psycho-pedagogical system analysis and the theory of the formation of mental actions.

Key words: pedagogometric, vital activity, cyclicity, system, phase, star Erzgammy, earth magnetism, applied physics, marine fleet.

Language: Russian

Citation: Mishchik SA (2017) SYSTEMIC PROBLEMS EARTH MAGNETISM OF APPLIED PHYSICS MARITIME FLOT OF PEDAGOGOMETRIC ANALYSIS. ISJ Theoretical \& Applied Science, 12 (56): $176-181$.

Soi: http://s-o-i.org/1.1/TAS-12-56-28 Doi: crossef https://dx.doi.org/10.15863/TAS.2017.12.56.28
\end{abstract}

УДК 372.851

\section{СИСТЕМНЫЕ ЗАДАЧИ ЗЕМНОГО МАГНЕТИЗМА ПРИКЛАДНОЙ ФИЗИКИ МОРСКОГО ФЛОТА ПЕДАГОГОМЕТРИЧЕСКОГО АНАЛИЗА}

Аннотация: рассмотрены основные принципы построения системных задач земного магнетизма прикладной физики морского флота педагогометрического анализа при формировании математических моделей учебной деятельности относительно характера достижения критериев жизнедеятельности, ичкличности, системности и этапности, которые образуют базисную ячейку образовательного пространства, а также применение двенадиати конечной звезды Эригаммы относительно представления принщипа эрцгаммности, который определит основы педагогометрики через формообразование предметными методами гиперпространства профессиональной жизнедеятельности, психологопедагогической теории деятельности, психолого-педагогического системного анализа и теории формирования умственньх действий.

Ключевые слова: педагогометрика, жизнедеятельность, цикличность, системность, этапность, звезда Эригаммы, земной магнетизм, прикладная физика, морской флот.

\section{Introduction}

Формирование системных задач земного магнетизма прикладной физики морского флота педагогометрического анализа связывается с решением общей задачи педагогометрики представление математических моделей учебной деятельности через базисный процесс методологии педагогометрического анализа, отражающего заданную структуру и форму жизнедеятельности, цикличности, системности и этапности.

педагогометрический анализ базисную ячейку образовательного пространства, которая представляет принцип эрцгаммности через всеобщую структуру двенадцати конечной звезды Эрцгаммы. Предложенная зависимость выражает основы педагогометрики через выделение предметных методов гиперпространства профессиональной жизнедеятельности, психолого-педагогической 
теории деятельности, психолого-педагогического системного анализа и теории формирования умственных действий $[1,2,3]$.

Выделенные основы подготовки инновационных широкопрофильных специалистов направлены на совершенствование базы предметных прикладных профессиональных задач земного магнетизма прикладной физики морского флота педагогометрического анализа, относительно проектной профессиональной деятельности на морском флоте. Проектирование математических моделей учебнопрофессиональной деятельности специалистов инновационного мышления ориентируется на: базисную звезду Эрцгаммы гиперпространства жизнедеятельности (Е1); базисный целостносистемный цикл жизнедеятельности (Е2); базисную звезду Эрцгаммы системного анализа (E3); базисное проявление двенадцати этапов и форм познавательного гиперпространства жизнедеятельности относительно образовательного процесса (E4) $[4,5,6]$.

Предложенные системные задачи земного магнетизма прикладной физики морского флота педагогометрического анализа и проектная база предметных педагогометрических моделей эрцгаммного анализа образовательных объектов с признаком базисно-нормативной эрцгаммности, определяют их обобщённые структуры. В данном случае формируется собственная функция психолого-математического представления профессионально-значимых объектов системных задач земного постоянного магнетизма прикладной физики морского флота педагогометрического анализа через объединение признаков смыслообразования учебнопрофессионального действия, его принятия, ориентировочно-исполнительно-контрольных признаков и прогноза совершенствования анализа объектов педагогометрческого содержания $[7,8,9]$.

\section{Materials and Methods}

Системные задачи земного магнетизма прикладной физики морского флота выделяют целостно-системное моделирование основных элементов транспортных технических объектов. Это моделирует формирование сознательной ориентации на единство базисных характеристик предметных и исполнительных условий относительно предмета содержания и способа его реализации через представление базисной ячейки образовательного пространства, выражающего принцип эрцгаммности адекватного структуре двенадцати конечной звезды Эрцгаммы. Рассматриваются: расчёт горизонтальной составляющей напряженности магнитного поля Земли; компенсация магнитного поля Земли с помощью колец Гельмгольца; определение магнитной индукции поля внутри судового соленоида; расчёт величины зоны застоя картушки магнитного компаса; определение длительности переходного процесса по периоду затухающих колебаний картушки компаса на морском флоте [10, 11,12].

В процессе решения системных задач земного магнетизма прикладной физики морского флота необходимо применять основные положения теории деятельности, системного анализа и теории формирования интеллекта через построение математических моделей учебнопрофессиональной активности отражающей структуру: базисной звездой Эрцгаммы гиперпространства жизнедеятельности (E1); базисного целостно-системного циклом жизнедеятельности $(\mathrm{E} 2) ;$ базисной звездой Эрцгаммы системного анализа (Е3); базисного проявления двенадцати этапов и форм познавательного гиперпространства жизнедеятельности относительно образовательного процесса (E4).

Системный анализ предполагает выполнение последовательности системных аналитических действий: выделить объект анализа - задачу земного магнетизма прикладной физики морского флота (ЗЗМПФМФ) как систему; установить порождающую среду ЗЗМПФМФ; определить уровни анализа ЗЗМПФМФ; представить целостные свойства ЗЗМПФМФ относительно про-странственных, и временных характеристик и их комбинаций; выделить структуру уровня анализа ЗЗМПФМФ; установить структурные элементы уровня анализа ЗЗМПФМФ; определить системообразующие связи данного уровня анализа ЗЗМПФМФ; представить межуровневые связи анализа ЗЗМПФМФ; выделить форму организации ЗЗМПФМФ; установить системные свойства и поведение ЗЗМПФМФ.

\section{Задача 1}

В судовой электронной системе по длинному вертикальному проводнику сверху вниз направляется сила тока $\boldsymbol{I}=\boldsymbol{8} \boldsymbol{A}$. На каком расстоянии $\boldsymbol{a}$ от проводника судовой электронной системы напряженность магнитного поля, получающегося от сложения земного магнитного поля и поля тока, направлена вертикально вверх? Горизонтальная составляющая напряженности земного поля $\boldsymbol{H}_{\mathbf{\Gamma}}=16 \mathrm{~A} / \mathbf{M}$.

Ответ: $a=0,08 \mathrm{~m}$.

\section{Задача 2}

В судовой электронной системе конденсатор

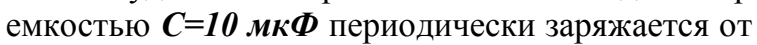
батареи с э. д. с. $\boldsymbol{\varepsilon}=\mathbf{1 0 0} B$ и разряжается через катушку в форме кольца диаметром $\boldsymbol{D}=\mathbf{2 0} \boldsymbol{c m}$, причем плоскость кольца совпадает с плоскостью 
магнитного меридиана. Катушка судовой электронной системы имеет $N=32$ витка. Помещенная в центре катушки горизонтальная магнитная стрелка отклоняется на угол $\alpha=45^{\circ}$. Переключение конденсатора судовой электронной системы происходит с частотой $\boldsymbol{n = 1 0 0 ~ Г ц . ~ О п р е д е л и т ь ~ п о ~ р е з у л ь т а т а м ~ и з м е р е н и и ̆ ~}$ горизонтальную составляющую $\boldsymbol{H}_{\mathbf{r}}$ напряженности магнитного поля Земли.

Ответ: $H_{\Gamma}=16 \mathrm{~A} / \mathrm{M}$.

\section{Задача 3}

В судовой электронной системе алюминиевый провод площадью поперечного сечения $\boldsymbol{S}=\boldsymbol{1} \boldsymbol{m . M}^{2}$ подвешен в горизонтальной плоскости перпендикулярно к магнитному меридиану, и по нему следует сила тока (с запада на восток) $\boldsymbol{I}=1,6 \boldsymbol{A}$. Какую долю от силы тяжести, действующей на провод судовой электронной системы, составляет сила, действующая на него со стороны земного магнитного поля? На сколько уменьшится сила тяжести, действующая на единицу длины провода судовой электронной системы, вследствие этой силы? Горизонтальная составляющая напряженности земного магнитного поля $\boldsymbol{H}_{\Gamma}=15 \mathrm{~A} / \mathrm{M}$.

Ответ: доля от силы тяжести 0,125\%; сила тяжести уменьшится на $3,2.10^{-5} \mathrm{H}$.

\section{Задача 4}

Горизонтальная составляющая магнитного поля Земли равна $\boldsymbol{H}_{\mathbf{r}}=\mathbf{1 6} \boldsymbol{A} / \boldsymbol{s}$. Рассчитать размеры судовых колец Гельмгольца, позволяющих скомпенсировать магнитное поле Земли, если сила тока в каждой судовой катушке кольца Гельмгольца равна $\boldsymbol{I}=\mathbf{2 0 0} \boldsymbol{M A}$, а число витков рано $\boldsymbol{\omega}=\mathbf{5 0}$ витков.

\section{Ответ:}

$$
B_{\mathrm{cp}}=\frac{2 \mu_{0} i w a^{2}}{2\left(a^{2}+a^{2} / 16\right)^{3 / 2}}=\frac{0,913 \mu_{0} i w}{a}
$$

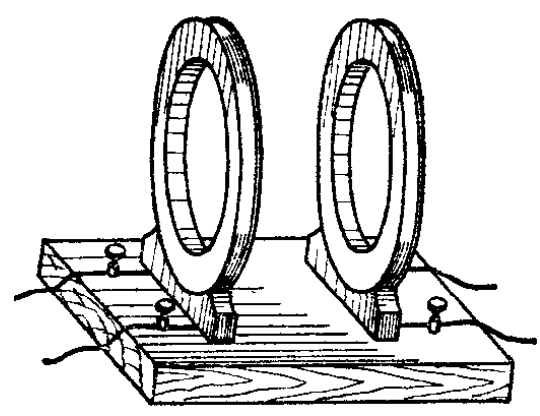

Рисунок 1 - Компенсационные кольца Гельмгольца.

\section{Задача 5}

Горизонтальная составляющая индукции магнитного поля Земли $\boldsymbol{B}_{1}=\mathbf{1 8} \boldsymbol{м \kappa} \boldsymbol{T}$. Магнитная стрелка судового компаса совершает в магнитном поле Земли малые колебания с периодом $\boldsymbol{T}_{\boldsymbol{l}}=\mathbf{8 , 9 2}$ c. При помещение магнитная стрелка судового компаса во внутрь судового соленоида, стрелка колеблется с периодом $\boldsymbol{T}_{2}=\mathbf{0 , 6 8} \boldsymbol{c}$. Определить магнитную индукцию $\boldsymbol{B}_{2}$ поля внутри судового соленоида.

Ответ: $B_{2}=3,1$ м

\section{Задача 6}

Определить длительность $\boldsymbol{t}_{\boldsymbol{n}}$ переходного процесса, если период затухающих колебаний

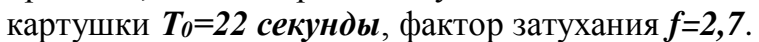
Начальное отклонение картушки от меридиана $A_{\boldsymbol{H}}=30^{0}$, а угол застоя $\boldsymbol{\alpha}=0,3^{0}$.

Ответ: $t_{n}=51,2 c$.

Задача 7

Определить величину зоны застоя картушки магнитного компаса, имеющей магнитный момент $\boldsymbol{M}=\mathbf{2} \boldsymbol{A} \cdot \boldsymbol{M}^{2}$, если напряжённость $\boldsymbol{H}^{\prime}$ судового магнитного поля составляет $12 \mathrm{~A} / \boldsymbol{M}$, момент $\boldsymbol{M}_{\boldsymbol{m}}$ сил сухого трения равен $\mathbf{1 , 5} \cdot 10^{-7} \boldsymbol{H} \cdot \boldsymbol{M}$, а магнитная проницаемость среды $\mu_{0}=1,26 \cdot 10^{-6}$ $H / A^{2}$.

Ответ: $\alpha_{4}=0,28^{0}$.

\section{Задача 8}

В судовой электронной системе по длинному проводу, протянутому перпендикулярно плоскости магнитного меридиана в направлении на запад, следует сила тока I=15 Aмnер. Напряжённость магнитного поля Земли в данном месте равна $\boldsymbol{H}=\mathbf{4 0} \boldsymbol{A} / \boldsymbol{M}$, а угол наклона составляет $\boldsymbol{\alpha}=\mathbf{7 0 ^ { \circ }}$. 1). Укажите точку вблизи середины провода судовой электронной системы, в которой напряжённость результирующего магнитного поля равна нулю. 2). Определить напряжённости результирующего магнитного поля на $\boldsymbol{a}=\mathbf{5} \boldsymbol{c m}$ выше и ниже провода судовой электронной системы.

Ответ: 1). на 2,1 см ниже и на 5,6 cм южнее; 2). $72 \mathrm{~A} / \mathrm{m} ; 50 \mathrm{~A} / \mathrm{s}$

Задача 9 
Магнитный момент стрелки судового компаса $\mathfrak{M}$, ее масса $\boldsymbol{m}$, длина $\boldsymbol{\ell}$. Горизонтальная составляющая магнитного поля Земли равна $\boldsymbol{H}$. Рассматривая магнитную стрелку судового компаса как тонкий стержень, определить период $\boldsymbol{T}$ колебаний стрелки судового компаса в магнитном поле Земли.

$$
\text { Ответ: } T=\pi l \sqrt{m /(3 \mathfrak{M H})} \text {. }
$$

\section{Задача 10}

Судовой магнит с магнитным моментом $\mathfrak{M}$. в виде цилиндрического стержня массы $\boldsymbol{m}$ и радиуса $\boldsymbol{R}$ подвешен за свою середину перпендикулярно к оси просверлено очень малое отверстие, в котором закреплена нить. Определить расположение стержня судового магнита в магнитном поле Земли, горизонтальная и вертикальная составляющие которого соответственно равны $\boldsymbol{H}_{\boldsymbol{\Gamma}}$ и $\boldsymbol{H}_{\boldsymbol{B}}$.

$$
\text { Ответ: } \operatorname{tg} \beta=\left(m g R+H_{\mathrm{r}} \mathfrak{M}\right) /\left(\mathfrak{M} H_{\mathrm{B}}\right) \text {. }
$$

\section{Conclusion}

Основные направления формирования и развития инновационного широкопрофильного профессионального мышления ориентируются на организацию всестороннего развития педагогометрической эрцгаммности. Представленные системные задачи земного магнетизма прикладной физики морского флота педагогометрического анализа устанавают основные направления развития и совершенствования базы прикладных предметных педагогометрических моделей образовательных объектов относительно педагогометрического математического моделирования учебного процесса. Формируемая образовательная деятельность связывается с процессами совершенствования программируемых математических моделей учебной активности относительно характера достижения критериев жизнедеятельности, цикличности, системности и этапности $[13,14$, 15].

Представленные содержательные задачи педагогометрического анализа по земному магнетизму ориентируются на выработку целостно-системного цикла жизнедеятельности, отражающего последовательность выполняемых фазовых состояний реализации данных учебного процесса, характеризующего исследуемые образовательные явления и представленных во времени в форме различных математических моделей.

Формирование целостно-системного цикла жизнедеятельности есть многоэтапный процесс. Преобразование внешнего образа мира во внутренний происходит в результате постепенной различно функциональной деятельности, которая отражает базисные рефлекторно-физиологические этапы процесса интериоризации относительно общего процесса познания. Педагогометрический анализ данных процессов позволит проводит плановое моделирование условиями подготовки широкопрофильных специалистов и управление формированием профессиональных качеств личности.

Определение в качестве базисного этапа формирования целостно-системной внутренней деятельности процесса ориентации, отражает предметный смысл всей психологопедагогической науки относительно подготовки современных целостно-системных широкопрофильных специалистов, имеющих высший уровень целостно-системной ориентировки в социально-экономических, технических и естественных системах.

Реализация

поставленных педагогометрических задач происходит через последовательность системных педагогометрических действий. Психологопедагогический системный анализ занимает базисную позицию в формировании целостносистемной личности и её профессионального образа - специалиста широкого профиля.

Психолого-педагогометрический системный анализ является одним из базисных средств процесса формирования специалиста широкого профиля - профессионального образа целостносистемной личности. Множество действий системного анализа определяют общую технологию решения выделенной проблемы. Важным действием психологопедагогометрического системного анализа является процесс установления порождающей среды, формирующей начальную фазу процесса исследования.

Порождающая среда выступает в различных качествах; от генетических до функциональных; от материальных до идеальных; от теоретических до практического решения проблемы. С точки зрения психолого-педагогометрического системного анализа порождающая среда определяет такие теоретико-практические проблемы, которые требуют радикального решения выде-ленных задач контрастными формулировками, задающих проблемность ситуации. При этом применяется принцип разномасштабного представления в пространственной и временной интерференции выбранных фактов.

Теоретические и эмпирические подходы в определении порождающей среды устанавливают уровни базисности и фундаментальности как предлагаемой модели представления проблемы, 
так и характера анализируемых отношений между фактами практического уподобления. Поэтому сам системный педагогометрический подход предъявляет строго заданный алгоритм действий и операций установления порождающей среды. Если педагогометрическое действие системного анализа по определению объекта как системы в конкретной форме требует заданного операционного состава последовательностей, то процесс средоопределения предлагает многовариантный подход в подборе каждого элемента системы в зависимости от глубины проработки модели.

Установление порождающей среды происходит через три циклических этапа. На первом этапе устанавливается соответствие между выделенными структурными элементами системы, как соответствующей фазы проработки первого действия, так и множеством рассматриваемых фактов окружающего материально-социального пространства. На втором этапе организуется про-цесс стабильного выполнения формируемой функции при непосредственном влияние выбранных внешних структурных параметров. На третьем этапе вводятся дополнительные внешние изменения, которые изменяют стабильную функцию системы. При этом ставится задача определения уровня автоматического управления системой при дестабилизации связи объект-среда. В целом, эти фазы подчёркивают существование деятельностных основ порождающей среды относительно ориентировочного, исполнительного и контрольного компонетов операционного состава.

Общая карта формирования порождающей среды также отражает общий циклический характер процесса формирования всего предметно-деятельностного цикла учебнопрофессионального познания. Можно создать своеобразный банк порождающих средовых данных, которые надо формировать по принципу целостной системности относительно фазы развития образовательного процесса. Тогда возникает инвариантная форма существования и функционирования порождающей среды. Уровень целостно-системного соответствия между выделенной системой и порождающей средой позволит в дальнейшем сформировать корреляционные педагогометрические функции математического анализа динамики всего учебновоспитательного процесса.

Следующее действие психологопедагогометрического системного анализа установление порождающей среды - задаёт историческую форму существования и развития целостно-системной личности относительно целостно-системного цикла жизнедеятельности. Это устанавливает новые формы теоретической и практической профессионального фундаментальной направленности.

Теоретический учебный материал средообразующего характера задаёт общую схему системного анализа выделенных качеств, когда с историческим оттенком представляется вся порождающая среда: весь базисноисторический массив отражается как системное образование; отбираются генетические факты, которые определяют весь смысл возникающей проблемы; устанавливаются внешние свойства элементов целостно-системного цикла; представляются уровни исторического анализа познавательных событий; отбирается уровневая структура, выделенного соответствия; устанавливаются структурные фактор-элементы заданного уровня; отражается порождающие, системообразующие связи данного уровня сложности; отбираются межуровневые связи историко-генетического характера; устанавливаются формообразующие элементы порождающей среды относительно современных структурных форм; представляются переходные системные свойства среды по параметрам сложности, разнообразия и упорядоченности; отражается статическое, динамическое и переходное поведение среды относительно исторического анализа; отбираются перспективные прогнозы, подтверждённые историческим развитием учебно-воспитательного процесса.

Процесс формирования данного действия системного анализа по установлению порождающей среды имеет поэтапную отработку с целью воспитания общей структуры целостносистемного цикла жизнедеятельности. Традиционные этапы формирования дополняются расширенными сенсорными способностями: акустическими, колористическими, термодинамическими, рецепторными, обонятельными и общими ориентационными.

В целом, возникает система практических и лабораторных работ по учебным курсам, когда тип учебных задач и практикумов задаётся видом и этапом формирования данного действия системного анализа, когда выделяется порождающая среда по воспитанию целостносистемной личности относительно формирования основных форм знания: мотивационной, ориентационной, материальной, внешнеречевой, вербально-знаковой и их дополнительных шести форм, которые отражают общий механизм существования не просто метода учебнопрофессионального развития, а выражают генезис развития смысла - генеральной линии экспозиции развития целостно-системной 
широкопрофильной личности, спроектированной педагогометрическими функциями математического моделирования при реализации международных образовательных стандартов морского образования алигорамной формы эревнометрического содержания.

\section{References:}

1. Mishchik SA (2014) Pedagogometrika and mathematical modeling educational activity. Materialy Mezhdunarodnoy nauchnoy konferenctsii "Modern mathematics in science" - 30.06.2014. ISJ Theoretical \&Applied Science 6(14): 54-56 Caracas, Venezuela. doi: http://dx.doi.org/10.15863/TAS.2014.06.14.10

2. Mishchik SA (2014) Simulation training activity methods of mathematical logic. Materialy Mezhdunarodnoy nauchnoy konferenctsii "Eurapean Science and Education" - 30.07.2014. ISJ Theoretical \&Applied Science 6(15): 72-74 Marseille, France. doi: http://dx.doi.org/10.15863/TAS.2014.07.15.13

3. Mishchik SA (2014) Mathematical modeling system integrity-cycle of life activity - first goal pedagogometriki. Materialy Mezhdunarodnoy nauchnoy konferenctsii "European Applied Sciences" - 30.08.2014. ISJ Theoretical \&Applied Science 7(16): 77-79. Aix-en-Provence, France. doi: http://dx.doi.org/10.15863/TAS.2014.08.16.13

4. Mishchik SA (2014) Mathematical modeling system integrity-curricular activities - the second problem pedagogometriki. Materialy Mezhdunarodnoy nauchnoy konferenctsii "European Innovation" - 30.09.2014. ISJ Theoretical \&Applied Science 9(17): 126-128 Martigues, France. doi: http://dx.doi.org/10.15863/TAS.2014.09.17.21

5. Mishchik SA (2014) Mathematical modeling holistic-systemic communicative activity - the third task pedagogometriki. Materialy Mezhdunarodnoy nauchnoy konferenctsii "European Scientific Achievements" 30.10.2014. ISJ Theoretical \&Applied Science 10(18): 45-47 Brighton, UK. doi: http://dx.doi.org/10.15863/TAS.2014.10.18.11

6. Mishchik SA (2014) Mathematical modeling integrity - system performance subject - fourth task pedagogometriki. Materialy Mezhdunarodnoy nauchnoy konferenctsii "Eurapean Science and Technology" 30.11.2014. ISJ Theoretical \&Applied Science 11(19): 51-54 Southampton, UK. doi: http://dx.doi.org/10.15863/TAS.2014.11.19.10

7. Mishchik SA (2015) Pedagogometrik - science and academic subject. Materialy Mezhdunarodnoy nauchnoy konferenctsii "European Technology in Science" 28.02.2015. ISJ Theoretical \& Applied Science
02 (22): 103-106 Malmö, Sweden. doi: http://dx.doi.org/10.15863/TAS.2015.02.22.17

8. Irodov I.E. (1979) Zadachi po obshhej fizike. M.: Nauka, 1979. - p.368.

9. Tokmazov GV (2014) Matematicheskoe modelirovanie $\mathrm{v}$ uchebno-professional'noy deyatel'nosti. Materialy Mezhdunarodnoy nauchnoy konferentsii «Modern mathematics in science» - 30.06.2014. ISJ Theoretical \& Applied Science 6(14): 44-46. - Caracas, Venezuela. doi: http://dx.doi.org/10.15863/TAS.2014.06.14.8

10. Tokmazov GV (2014) Mathematical modeling research skills in educational activity methods of probability theory. Materialy Mezhdunarodnoy nauchnoy konferenctsii "Eurapean Science and Technology" 30.11.2014. ISJ Theoretical \&Applied Science 11(20): 66-69 Southampton, United Kingdom. doi: http://dx.doi.org/10.15863/TAS.2014.11.19.13

11. Mishhik N.A. (2016) Pravovy'e osnovy' francuzskoj si-stemy' bor'by' s zagryazneniem morya / Nauchny'e issledovaniya: Informaciya, analiz, prognoz [Tekst]: monografiya / [V.E'.Lebedev, A.A.Sviridenko, V.M.Sokolinskij i dr.]; pod obshhej red. prof. O.I.Kirikova - Kniga 51.- Voronezh-Moskva, 2016.

12. Mishchik NA (2014) The practice of french justice article 228 of the UN convention on the law of the sea. Materialy Mezhdunarodnoy nauchnoy konferenctsii "The European Science and Education"- 30.07.2014. ISJ Theoretical \& Applied Science 07 (15): 93-97. - Marseille, France. doi: http://dx.doi.org/10.15863/TAS.2014.07.15.19

13. Mishhik N.A., Antonenko G.A. (2013) Liniya gorizonta kak gradientny'j perepad $\mathrm{V}$ fotograficheskix izmereniyax dlya celej morexodnoj astronomii//E'kspluataciya morskogo transporta. 2013. № 2 (72). Novorossijsk, p. 23-28.

14. Mishhik N.A. (2000) Optimizaciya metodov morexodnoj astronomii [Tekst]: avto-ref.dis. ... kand. tex. nauk: 05.22.16 / N.A.Mishhik. Novorossijsk, 2000. - 24 p.

15. Mishhik N.A. (2000) Optimizaciya metodov morexodnoj astronomii [Tekst]: dis. ... kand. tex. nauk: 05.22.16 / N.A.Mishhik. Novorossijsk, 2000. - 188 p. 